\title{
RIM NA SINDROME DE MAYER-ROKITANSKY-KÜSTER-HAUSER
}

\section{KIDNEY ON MAYER-ROKITANSKY-KÜSTER-HAUSER SYNDROME}

DOI: $10.5380 /$ rmu.v1i1.40685

Giovanni Luís Breda', Henrique Guesser Ascenço', Maurício Carvalho

\section{RESUMO}

A síndrome de Mayer-Rokitansky-Küster-Hauser (MRKH) é afecção rara, caracterizada por agenesia congênita de terço superior da vagina e ausência ou atresia uterina. Sua prevalência varia de 1:4000 a 5000 nascimentos de bebês do sexo feminino. Associa-se frequentemente a outras alterações, como anomalias renais ou malformações esqueléticas. Neste relato apresentamos uma paciente com síndrome de MRKH, nefrectomizada por provável displasia renal, com hipercalciúria e litíase em rim único.

Palavras chave: Anormalidades congênitas, hipercalciúria, nefrolitíase.

\section{ABSTRACT}

The Mayer-Rokitansky-Küster-Hauser syndrome (MRKH) is a rare disorder characterized by congenital absence of upper part of the vagina and the absence or atresia of the uterus. The prevalence has been reported as one in 4000-5000 female births. It is often associated with other alterations such as renal abnormalities or skeletal malformations. In this report we present a patient with MRKH syndrome, nephrectomized by probable kidney dysplasia, with hypercalciuria and nephrolithiasis in the remanescent kidney.

Key-words: Congenital abnormalities, hypercalciuria, nephrolithiasis.

\author{
1-Universidade Federal do Paraná \\ Contato do Autor / Mail to: \\ Maurício Carvalho carvalho@mais.sul.com.br \\ Rua General Carneiro, 181 - Alto da Glória Curitiba - PR, 80060-900, 10 Andar, Departamento de Clínica Médica
}




\section{RELATO DO CASO}

Paciente de 24 anos, feminina, branca, casada, com história de correção de bexiga hipoplásica e nefrectomia à direita, por provável "malformação renal" (sic), aos 20 dias de vida. Na investigação de amenorréia primária, durante sua adolescência, foi notado ao exame ginecológico vagina em fundo cego e útero pouco desenvolvido. Relatava nos últimos 11 meses quatro episódios de dor lombar à esquerda, de forte intensidade, em cólica, com irradiação para região inguinal ipsilateral. Há 15 dias da internação apresentou disúria, polaciúria, urina turva, febre $\left(38^{\circ} \mathrm{C}\right)$ e sinal de Giordano positivo à esquerda. Urocultura na ocasião foi positiva para Escherichia coli. Recebeu tratamento com ciprofloxacina, houve boa evolução clínica e foi então encaminhada ao Hospital de Clínicas da UFPR. Os dados vitais no momento da admissão, bem como pressão arterial e exame físico segmentar, foram normais. O exame ginecológico revelou caracteres sexuais secundários e genitália externa de aspecto normal, com vagina em fundo cego, de profundidade normal. O colo uterino não foi visualizado. No toque vaginal, não se palpou útero ou anexos.

A creatinina plasmática foi de $0,9 \mathrm{mg} / \mathrm{dl}$. As dosagens séricas de uréia, sódio, cálcio, fósforo, potássio, ácido úrico, albumina e bicarbonato foram normais. A análise de urina de 24 horas revelou hipercalciúria $(282,5 \mathrm{mg} /$ dia), com citratúria, oxalúria e uricosúria dentro dos valores de referência. A ecografia abdominal confirmou a ausência do rim direito e mostrou rim esquerdo tópico, vicariante, com forma, contornos e parênquima normais e imagem sugestiva de cálculo no grupo calicial inferior, de $8 \mathrm{~mm}$ no maior diâmetro e presença de útero rudimentar não cavitado. Realizou também tomografia computadorizada abdominal, que demonstrou rim direito ausente, rim esquerdo com dimensões aumentadas, com imagem hiperdensa em seu terço inferior (Figura 1). Foi submetida à sessão de litotripsia extracorpórea (LECO), com fragmentação satisfatória do cálculo. Raios $X$ simples de abdome de controle pósLECO não evidenciou concreção radio-opaca

\section{DISCUSSÃO}

A síndrome de MRKH é na maioria dos casos de ocorrência esporádica e sua causa é desconhecida. Postulam-se como fatores desencadeantes ativação de subtância inibidora ou a gênese de algum hormônio anti-mülleriano ${ }^{2}$. Raros casos de agregação familiar têm sido relatados ${ }^{5}$. Inativação de genes da família Wnt (ricamente expressos nos ductos de Müller) e mutações de genes HOX (presentes nos ductos de
Müller e nas fases iniciais de diferenciação renal e esquelética) também têm sido estudados ${ }^{3}$.

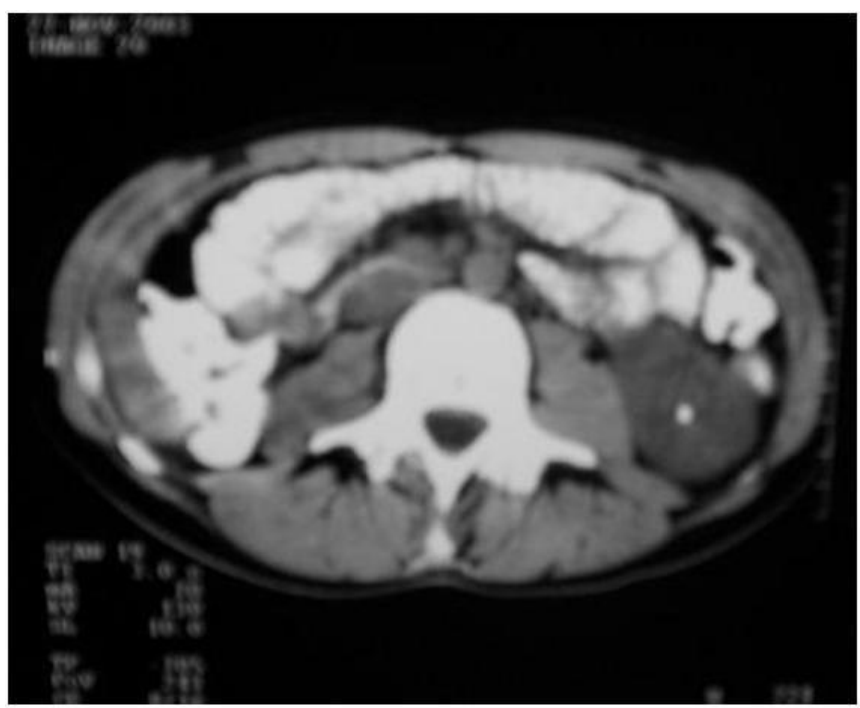

Figura 1: TAC demonstra ausência de rim direito e rim esquerdo com dimensões aumentadas, com imagem hiperdensa em seu terço inferior

Várias malformações associadas à síndrome de MRKH são descritas ${ }^{6}$. As alterações renais são frequentes, ocorrendo em mais de um terço dos casos. Agenesia, displasia e ectopia renal são as alterações mais encontradas ${ }^{7}$. Rim em ferradura, rim pélvico, anormalidades dos sistemas coletores ou má rotação renal são achados menos comuns ${ }^{4,8}$. Raramente, a síndrome de MRKH pode evoluir para insuficiência renal crônica ${ }^{9,10}$. Em $12 \%$ dos casos também ocorrem anomalias no desenvolvimento do sistema esquelético, sendo que dois terços dos casos envolvem alterações da coluna vertebral ${ }^{2}$.

Algumas síndromes genéticas compartilham alterações no desenvolvimento dos ductos de Müller, anomalias renais e esqueléticas. A síndrome de KlippelFeil apresenta adicionalmente assimetria facial, surdez e escoliose; a síndrome VATER (defeitos Vertebrais; atresia Anal; fístula Traqueo-Esofágica; malformação Renal) e a síndrome de Winter, caracterizada por atresia vaginal, agenesia renal uni ou bilateral e surdez, são outros exemplos ${ }^{3}$.

A prevalência de nefrolitíase aumentou nos últimos 20 anos, passando de 3,2 a 5,2\% da população em alguns estudos. Além disso, apresenta taxas de recorrê-cia ao redor de $50 \%$ em seguimentos de 5 a 10 $\operatorname{anos}^{11}$. A maioria dos cálculos renais são compostos por cálcio, principalmente em associação com oxalato. Hipercalciúria, e conseqüente saturação urinária por sais de cálcio, é o distúrbio metabólico mais frequentemente associado à calculose renal. Estes fatores são provavelmente os responsáveis pela associação de hipercalciúria e nefrolitíase nesta paciente. 


\section{REVISTA MÉDICA DA UFPR}

Poucos trabalhos analisaram a evolução da doença litiásica em portadores de rim único. Worcester e colaboradores estudaram 115 pacientes com rim único e nefrolitíase ${ }^{12}$. Quase $50 \%$ dos casos eram mulheres, com nefrectomias indicadas por obstrução, infecção ou cálculos de grande volume, formados em sua maioria por fosfato de cálcio ou estruvita. A presença de rim único não piorou a evolução da doença litiásica quando comparada a portadores de ambos os rins. Entretanto, houve maior perda de função renal ao longo do tempo no subgrupo de homens com idade abaixo de 45 anos. O tratamento com LECO foi realizado com sucesso no caso aqui descrito e não houve complicações, semelhantes a outros relatos de litotripsia em rim único descritos na literatura ${ }^{13}$

Agenesia renal unilateral pode ser vista como modelo de redução do número de néfrons, avaliado como fator de risco para hipertensão ou diminuição de função renal. Em estudo recente, Seeman e colaboradores estudaram 29 crianças com agenesia renal unilateral ${ }^{14}$. Crianças que possuíam anormalidades ultrassonográficas ou cintilográficas no rim remanescente apresentaram frequência aumentada de hipertensão, proteinúria ou insuficiência renal. Ao contrário, nas crianças com rim remanescente normal não se evidenciou qualquer das anormalidades citadas. Na paciente aqui descrita, a pressão arterial estava normal, a função renal preservada e excreção de proteínas foi normal.

Em conclusão, atresia de porção superior da vagina e anormalidades uterinas caracterizam a síndrome de MRKH. A associação com malformações renais é frequente e deve ser cogitada. Neste caso, a associação com hipercalciúria e consequente nefrolitíase em rim remanescente constituiu fator de risco adicional. Monitorização clinica periódica é recomendada.

\section{REFERÊNCIAS BIBLIOGRÁFICAS}

1. Rosenberg HK, Sherman NH, Tarry WF, Duckett JW, Snyder HM. Mayer-Rokitansky-Kuster-Hauser Syndrome: US aid to diagnosis. Radiology 1986; 161:815-9.

2. Oppelt P, Renner SP, Kellermann A, Brucker S, Hauser GA, Ludwig KS, et al. Clinical aspects of Mayer-Rokitansky-KuesterHauser syndrome: recommendations for clinical diagnosis and staging. Hum Reprod 2006; 21:792-7.

3. Guerrier D, Mouchel T, Pasquier L, Pellerin I. The MayerRokitansky-Küster-Hauser syndrome (congenital absence of uterus and vagina) - phenotypic manifestations and genetic approaches. J Negat Results Biomed 2006; 27:5:1-8.

4. Strubbe EH, Willemsen WN, Lemmens JA, Thijn CJ, Rol-land R. Mayer-Rokitansky-Kuster-Hauser syndrome: dis-tinction between two forms based on excretory uro-graphic, sonographic, and laparoscopic findings. AJR Am J Roentgenol 1993; 160:331-4.
5. Jones HW Jr, Mermut S. Familial occurrence of congeni-tal absence of the vagina. Am J Obstet Gynecol 1972; 114:1100-1.

6. Raybaud C, Richard O, Arzim M: Mayer-Rokitansky-KusterHauster syndrome: associated pathologies. Arch Pediatr Nov; 8(11): 1209-1213, 2001.

7. Basile C, De Michele V. Renal abnormalities in MayerRokitansky-Kuster-Hauser syndrome. J Nephrol 2001; 14:316-8.

8. Tarry WF, Duckett JW, Stephens FD. The Mayer-Rokitansky syndrome: pathogenesis, classification and management. J Urol 1986; 136:648-52.

9. Villodres MJ, Galindo P, Palacios ME, Asensio C. Renal insufficiency and Rokitansky síndrome. Nefrologia 2004; 24:300-1.

10. Zerbi S, Orani MA, Bonforte G. End-stage renal disease in Mayer-Rokitansky-Kuster-Hauser syndrome. Nephron 2002; 92:752-3.

11. Moe OW. Kidney stones: pathophysiology and medical management. Lancet 2006; 367:333-44.

12. Worcester E, Parks JH, Josephson MA, Thisted RA, Coe FI Causes and consequences of kidney loss in patients with nephrolithiasis. Kidney Int 2003; 64:2204-13.

13. Jimenez Verdejo A, Arrabal Martin M, Mijan Ortiz J, San-chez Tamayo J, Lopez-Carmona Pintado F, Zuluaga Gomez A. Treatment of lithiasis in patients with one kidney by extracorporeal shock wave lithotripsy. Arch Esp Urol 1998; 51:709-1

14. Seeman T, Patzer L, John U, Dusek J, Vondrak K, Janda J, et al. Bood pressure, renal function, and proteinuria in chil-dren with unilateral renal agenesis. Kidney Blood Pressure Res 2006; 29: 210-15. 